OPEN ACCESS

Edited by:

Camille Eichelberger Granada, Universidade do Vale do

Taquari-Univates, Brazil

Reviewed by:

Juan Chen,

Northwest A\&F University, China

Jelena Marinkovic,

Institute of Field and Vegetable Crops,

Serbia

*Correspondence:

Richard Ansong Omari

richard.omari@zalf.de

Specialty section:

This article was submitted to

Plant Symbiotic Interactions,

a section of the journal

Frontiers in Plant Science

Received: 08 May 2021 Accepted: 16 December 2021

Published: 12 January 2022

Citation:

Omari RA, Yuan K, Anh KT,

Reckling $M$, Halwani $M$, Egamberdieva D, Ohkama-Ohtsu N and Bellingrath-Kimura SD (2022) Enhanced Soybean Productivity by Inoculation With Indigenous

Bradyrhizobium Strains in Agroecological Conditions of Northeast Germany.

Front. Plant Sci. 12:707080. doi: 10.3389/fpls.2021.707080

\section{Enhanced Soybean Productivity by Inoculation With Indigenous Bradyrhizobium Strains in Agroecological Conditions of Northeast Germany}

\author{
Richard Ansong Omari1,2*, Kun Yuan ${ }^{3}$, Khoa Trinh Anh ${ }^{4}$, Moritz Reckling ${ }^{1}$, \\ Mosab Halwani ${ }^{1}$, Dilfuza Egamberdieva ${ }^{1,5}$, Naoko Ohkama-Ohtsu ${ }^{4}$ and \\ Sonoko D. Bellingrath-Kimura ${ }^{1,2}$
}

\footnotetext{
${ }^{1}$ Leibniz Centre for Agricultural Landscape Research (ZALF), Müncheberg, Germany, ${ }^{2}$ Faculty of Life Sciences, Humboldt-University of Berlin, Berlin, Germany, ${ }^{3}$ Institute of Global Innovation Research (GIR), Tokyo University of Agriculture and Technology, Tokyo, Japan, ${ }^{4}$ Institute of Agriculture, Tokyo University of Agriculture and Technology, Tokyo, Japan, ${ }^{5}$ Faculty of Biology, National University of Uzbekistan, Tashkent, Uzbekistan
}

Commercial inoculants are often used to inoculate field-grown soybean in Europe. However, nodulation efficiencies in these areas are often low. To enhance biological nitrogen $(\mathrm{N})$ fixation and increase domestic legume production, indigenous strains that are adapted to local conditions could be used to develop more effective inoculants. The objective of this study was to assess the ability of locally isolated Bradyrhizobium strains to enhance soybean productivity in different growing conditions of Northeast Germany. Three indigenous Bradyrhizobium isolates (GMF14, GMM36, and GEM96) were tested in combination with different soybean cultivars of different maturity groups and quality characteristics in one field trial and two greenhouse studies. The results showed a highly significant strain $\times$ cultivar interactions on nodulation response. Independent of the Bradyrhizobium strain, inoculated plants in the greenhouse showed higher nodulation, which corresponded with an increased $\mathrm{N}$ uptake than that in field conditions. There were significantly higher nodule numbers and nodule dry weights following GMF14 and GMM36 inoculation in well-watered soil, but only minor differences under drought conditions. Inoculation of the soybean cultivar Merlin with the strain GEM96 enhanced nodulation but did not correspond to an increased grain yield under field conditions. USDA110 was consistent in improving the grain yield of soybean cultivars Sultana and Siroca. On the other hand, GMM36 inoculation to Sultana and GEM96 inoculation to Siroca resulted in similar yields. Our results demonstrate that inoculation of locally adapted soybean cultivars with the indigenous isolates improves nodulation and yield attributes. Thus, to attain optimal symbiotic performance, the strains need to be matched with specific cultivars. 


\section{INTRODUCTION}

Soybean [Glycine max (L.) Merr.] consumption as food and feed for livestock in Europe has increased significantly in recent decades, although domestic production has increased marginally. The European Union encourages domestic grain legume production to reduce reliance on imports, to minimize the negative environmental impacts associated with intensive cereal production (Watson et al., 2017), and to diversify cropping systems (Hufnagel et al., 2020). Meanwhile, most farmers in Europe prefer to invest in cereal crops due to the high economic returns and lower risk of losses compared with grain legumes (Voisin et al., 2013), although Reckling et al. (2018) found that their yield stability is similar to that of other spring crops. Soybean cultivation in Central Europe is still relatively new (Zimmer et al., 2016), despite an almost twofold increase in production area between 2013 and 2018 (Krautgartner et al., 2018). In Germany, while domestic soybean production is low, cultivation is mainly concentrated in the south with a small and almost non-existent contribution from the northern part. However, there is great potential to expand soybean production areas in some cool climates and non-traditional growing areas of Europe due to increasing temperatures (de Visser et al., 2014; Feng et al., 2021). A study by Karges et al. (2022) also highlighted the agro-economic prospects for expanding soybean production beyond its current northerly limit in Europe.

Biological $\mathrm{N}_{2}$ fixation (BNF) ensures the utilization of atmospheric nitrogen $(\mathrm{N})$, which translates into improved soil fertility, increased crop productivity, and an economically sustainable production system (Choudhury and Kennedy, 2004; Zander et al., 2016). Efficient BNF depends on proficient symbiotic interactions between the legume host and rhizobium in a range of environmental conditions that favor the activities of participating organisms. This interaction has implications for the stability of the performance of legume inoculants (Gunnabo et al., 2019) and thus reflects stable and increased legume production. Environmental stress factors such as temperature, drought, salinity, $\mathrm{pH}$, biotic competition, etc. affect both the host and rhizobium response, leading to a reduction in BNF efficiency (Laranjo and Oliveira, 2011; Goyal et al., 2021). According to Cernay et al. (2015), the high susceptibility of BNF to environmental stress factors is one of the major drivers of the high grain legume yield variability in Europe. Therefore, optimizing legume-rhizobium interactions by targeting inoculant strains to specific soybean cultivars presents a promising option to increase the efficiency of $\mathrm{N}$ symbiosis and crop productivity in Central Europe.

Although commercial rhizobia strains have in the past been used to inoculate field-grown soybean plants in Germany, nodulation efficiency has often been low compared with the origin where the strains were isolated (Kadiata et al., 2012; Schmidt et al., 2015). To enhance BNF and increase domestic legume production, native or indigenous rhizobium strains that are adapted to local conditions could be targeted for the development of inoculants. Genetically stable rhizobium strains to harsh soil conditions may enable higher BNF and increase grain yield in soybean compared with commercial inoculants (Hungria and Vargas, 2000; Rahmani et al., 2008). Yuan et al. (2020) successfully isolated promising rhizobium strains from arable fields in northern Germany. Some of the isolates in their pot experiment were tolerant to cold conditions and showed great potential to enhance soybean growth under low-temperature conditions. However, the effectiveness of these strains on soybean productivity has not yet been tested under field conditions in Germany.

Thus, for the selection of effective strains for future use as commercial inoculants to improve soybean production, there is a need to test the efficacy of the isolated strains of Yuan et al. (2020) under growing conditions in Central Europe. The goal of this study was to assess the ability of indigenous Bradyrhizobium strain(s) to enhance soybean productivity under varying growing conditions in Northeast Germany in greenhouse and field studies.

\section{MATERIALS AND METHODS}

\section{Description of the Study Site}

Two greenhouse experiments and one field trial were conducted at the experimental station at the Leibniz Center for Agricultural Landscape Research, Müncheberg, Germany $\left(52^{\circ} 31^{\prime} \mathrm{N} ; 14^{\circ} 7^{\prime} \mathrm{E}\right.$; $60 \mathrm{~m}$ ). Soils for both greenhouse and field studies were from sites with no previous soybean cropping history. The soil in the area is classified as Podzoluvisol to Arenosol and is located $62 \mathrm{~m}$ above sea level. The area is characterized by droughts in spring and summer. The mean annual precipitation is $533 \mathrm{~mm}$, and the mean long-term annual temperature is $8.5^{\circ} \mathrm{C}$.

\section{Trial Description}

\section{Greenhouse Experiment 1}

This greenhouse experiment was an initial screening intended to study the interaction effects of representative soybean cultivars of Central Europe and the different Bradyrhizobium isolates on nodulation and biomass development. Five soybean cultivars of different maturity groups, growth and quality characteristics, namely, Comandor (000), Merlin (000), Shouna (000), Sultana (000), and Siroca (00) (Table 1), were tested in combination with three indigenous Bradyrhizobium isolates (GMF14, GMM36, and GEM96) and compared with a non-inoculated control (Table 2). These are among the commonly cultivated cultivars in Central Europe. Bradyrhizobium isolates were previously isolated from arable soils in Northeast Germany (Fehrow and Müncheberg). A $4 \times 5$ factorial combination involving Bradyrhizobium isolates and soybean cultivars, respectively, in a complete randomized design was set for the study. Each treatment was replicated 3 times.

Each Bradyrhizobium isolate was cultured in yeast extract mannitol (YEM) liquid medium for 5 days at $28^{\circ} \mathrm{C}$. The cells were then concentrated and washed twice with sterile distilled water. Each bacterial suspension was adjusted to a concentration of $10^{8}$ cells $\mathrm{ml}^{-1}$.

Seeds of each cultivar were first surface-sterilized with 70\% alcohol for $1 \mathrm{~min}$, followed by $3 \%$ sodium hypochlorite for 2 min. The seeds were rinsed 8 times with sterile distilled water 
TABLE 1 | Characteristics of soybean cultivars.

\begin{tabular}{|c|c|c|c|c|c|c|c|c|}
\hline Cultivar & Date of registration & Maturity group & Maturity & Height & Growth type & Thousand-grain weight & Protein content & Oil content \\
\hline Comandor & 2016 & 000 & 5 & 5 & Semi-determinate & 4 & 5 & 5 \\
\hline Merlin & 1997 & 000 & 2 & 3 & Indeterminate & 1 & 5 & 7 \\
\hline Shouna & 2015 & 000 & 4 & 5 & Indeterminate & 3 & 6 & 5 \\
\hline Sultana & 2009 & 000 & 3 & 3 & Semi-determinate & 4 & 7 & 5 \\
\hline Siroca & 2017 & 00 & 5 & 4 & Semi-determinate & 5 & 7 & 4 \\
\hline
\end{tabular}

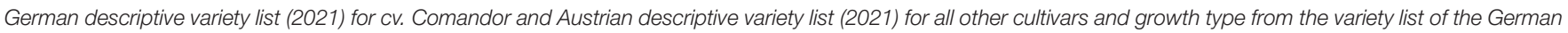
soybean association (2021).

TABLE 2 | Characteristics of Bradyrhizobium strains.

\begin{tabular}{|c|c|c|c|c|c|c|c|}
\hline Strain & Host cultivar & Sampling site & Classification (MSLA) & Growth & Temperature $\left({ }^{\circ} \mathrm{C}\right)$ & pH & $\mathrm{NaCl}(\%)$ \\
\hline GMF14 & Merlin & Müncheberg & Bradyrhizobium sp. & + & $4-37$ & $4.5-10$ & $4 \%$ \\
\hline GMM36 & Merlin & Müncheberg & Bradyrhizobium sp. & + & $15-37$ & $4.5-10$ & $0 \%$ \\
\hline GEM96 & Enrei & Fehrow & Bradyrhizobium sp. & + & $15-37$ & $4.5-10$ & $0 \%$ \\
\hline
\end{tabular}

Yuan et al. (2020).

to remove traces of alcohol and sodium hypochlorite. Seeds were then dried in sterile towel paper.

Each surface sterilized seed was inoculated by thoroughly mixing $65 \mathrm{ml}$ liquid culture with $1 \mathrm{~kg}$ seeds and allowing them to dry at room temperature for $2 \mathrm{~h}$ before sowing. Sowing was carried out on 10th September 2019. Three healthy seeds of uniform size were sown in each box $(10 \mathrm{~cm} \times 8 \mathrm{~cm} \times 8 \mathrm{~cm})$ containing $1 \mathrm{~kg}$ soil and were later thinned to one plant per box of comparable height and vigor after 2 weeks. Soybean plants were grown for 40 days (V5 growth stage) at an average temperature of $22^{\circ} \mathrm{C}$ under a 16 -h light and 8 -h dark photoperiod as employed by Yuan et al. (2020). The average relative humidity during the study was $50 \%$. Pots were watered to field capacity with distilled water at 4-day intervals until the termination of the experiment. No chemical fertilizers were applied during the growth of soybean plants. The physicochemical properties of the soil are presented in Table 3.

\section{Greenhouse Experiment 2}

This study was conducted to evaluate the extent to which the symbiotic performance of the Bradyrhizobium strains is

TABLE 3 | Selected physicochemical properties of the soil used.

\begin{tabular}{|c|c|}
\hline Variable (Unit) & Concentration \\
\hline Total carbon $\left(\mathrm{g} \mathrm{kg}^{-1}\right)$ & $6.5 \pm 0.71$ \\
\hline Total nitrogen $\left(\mathrm{g} \mathrm{kg}^{-1}\right)$ & $0.5 \pm 0.03$ \\
\hline Total sulfur $\left(\mathrm{g} \mathrm{kg}^{-1}\right)$ & $0.2 \pm 0.02$ \\
\hline Available phosphorus (mg $100 \mathrm{~g}^{-1}$ ) & $20.9 \pm 0.35$ \\
\hline Potassium (mg $\left.100 \mathrm{~g}^{-1}\right)$ & $12.1 \pm 0.87$ \\
\hline Magnesium (mg $100 \mathrm{~g}^{-1}$ ) & $1.4 \pm 0.08$ \\
\hline $\mathrm{pH}\left(\mathrm{H}_{2} \mathrm{O}\right)$ & 6.7 \\
\hline Sand (\%) & 61 \\
\hline Silt (\%) & 27 \\
\hline Clay (\%) & 12 \\
\hline
\end{tabular}

\pm , Standard deviation of means. impacted by varying soil moisture levels. Sultana, one of the cultivars that showed a moderate response to inoculation in greenhouse Experiment 1 in terms of nodulation and shoot biomass growth was used. The three Bradyrhizobium strains used in greenhouse Experiment 1 plus a reference strain (Bradyrhizobium diazoefficiens USDA110) were inoculated to Sultana under two moisture levels. Non-inoculated soybean seeds were used as a control.

Seed sterilization and inoculum preparation were performed as explained in greenhouse Experiment 1. In this study, inoculation was performed by mixing $10 \mathrm{~g}$ autoclaved peat $\left(141^{\circ} \mathrm{C}\right.$ for $24 \mathrm{~min}$ ) with $65 \mathrm{ml}$ liquid culture to form a slurry. Peat was added to reduce the excessive softening of the seed coat, which affected germination in greenhouse Experiment 1. Then, $1 \mathrm{~kg}$ soybean seeds were thoroughly mixed with the slurry until each seed was sufficiently coated. Sowing was carried out on 13th June 2020 as explained in greenhouse Experiment 1. The pots were arranged in a complete randomized design and each treatment was replicated four times.

Three days after sowing, two moisture levels namely wellwatered conditions (irrigation at $80 \%$ soil moisture) and drought conditions (irrigation at $40 \%$ soil moisture) were imposed on the respective treatment until termination of the study (50 days after sowing). Irrigation drippers were installed in each pot, and moisture was supplied when necessary. The well-watered treatment received $70 \mathrm{ml}$ of water 4-5 times a week. The drought treatment received $35 \mathrm{ml}$ of water 1-2 times a week. Soil moisture conditions were monitored with a UMP-1 BT soil moisture sensor (Umwelt-Geräte-Technik GmbH, Müncheberg, Germany) (Egamberdieva et al., 2019). Similar growth conditions as greenhouse Experiment 1 were set for this study.

\section{Field Trial}

This study was intended to evaluate different soybean cultivar responses to Bradyrhizobium strain inoculation under field conditions. Three soybean cultivars adapted to Northeast Germany from the list of cultivars used in greenhouse Experiment 1 were selected for this study. They were tested 
in combination with four Bradyrhizobium strains (GMF14, GMM36, GEM96, and USDA110 (same strains used in greenhouse Experiment 2) and a non-inoculated control. The treatments were laid out in a randomized complete block design with $5 \times 3$ factorial combinations of Bradyrhizobium and soybean cultivars, respectively, and each treatment was replicated six times. The trial was conducted in the 2020 cropping season (May-October) at the site where soil for both greenhouse experiments was collected.

Soybean seed sterilization, inoculum preparation, formulation, and inoculation were performed as explained in greenhouse Experiment 2. Each plot size measured 11.5 $\mathrm{m} \times 1.8 \mathrm{~m}$, and alleys of 3.5 and $0.5 \mathrm{~m}$ were left between blocks and plots, respectively. Soybean seeds were sown at 80 seeds $\mathrm{m}^{-2}$ at a spacing of $37.5 \mathrm{~cm}$ between rows on 5th May 2020. To avoid cross-contamination, the plot seeder was thoroughly cleaned after each treatment with a different inoculant by following a modified approach of Zimmer et al. (2016). First, $3 \mathrm{~kg}$ of barley seeds were treated with $70 \%$ alcohol and immediately run through the seeder, followed by a thorough cleaning with pneumatic pressure. Blanket phosphorus, potassium, magnesium, and sulfur fertilizer $(\mathrm{P} / \mathrm{K} / \mathrm{Mg} / \mathrm{S} \quad 9: 42: 2: 10)$ and kieserit $(\mathrm{Mg} / \mathrm{S} 30: 40)$ were applied to the field at $200 \mathrm{~kg}$ $\mathrm{ha}^{-1}$ before sowing.

\section{Measurements}

In both greenhouse studies, plant shoots were cut with scissors at $1 \mathrm{~cm}$ above the soil surface. Then, the soil in each pot was emptied on a white sheet covered with transparent plastic material. The plant was carefully removed to obtain unharmed roots and nodules. All adhering soil particles were rinsed off with a stream of water, and nodules were gently detached from the roots. The number of nodules on the roots was manually counted. All fresh nodules and shoot samples were dried in an oven at $60^{\circ} \mathrm{C}$ for $48 \mathrm{~h}$. The dry weights of all samples were determined with a weighing balance. Dry shoot samples were later milled for the determination of shoot $\mathrm{N}$ uptake.

In the field trial, aboveground biomass samples were collected from two inner rows of each plot $0.5 \mathrm{~m}$ in length at the $\mathrm{R} 3$ growth stage. Five plants from the inner rows of each plot were randomly selected, and their roots together with nodules were gently excavated with a spade. The shoot dry weight, nodule number, nodule dry weight, and shoot $\mathrm{N}$ uptake were determined as was conducted in both greenhouse studies. At physiological maturity, all soybean plants were harvested with a plot combine harvester. Grain yield $\left(\mathrm{kg} \mathrm{ha}^{-1}\right)$ and thousand grain weight (TGW) were determined at $86 \%$ dry matter. Shoot $\mathrm{N}$ analysis was performed by the dry combustion method using a CNS elemental analyzer (Leco Instruments $\mathrm{GmbH}$ ). The crude protein and oil contents in the grains were measured with near-infrared reflectance spectroscopy (NIRS) (Inframatic 9500, Perten Instruments, Sweden).

Soil sampling was performed before sowing at $0-15 \mathrm{~cm}$ depth from up to 12 random points. They were then passed through a 2 $\mathrm{mm}$ mesh and air-dried before further analyses. Total soil carbon, $\mathrm{N}$, and sulfur were determined by dry combustion using a CNS elemental analyzer. Phosphorus, potassium, and magnesium contents were analyzed by ICP-OES (iCAP 6300 DUO, Thermo Fisher Scientific GmbH) via the Mehlich-3 extraction method (Sims, 2009). Soil pH was measured in a 1:2(v/v) soil-water suspension with a Robotic Titrosampler (Deutsche Metrohm $\mathrm{GmbH} \& \mathrm{Co} ., \mathrm{KG})$. The particle size distribution was determined by wet sieving and sedimentation with the Köhn-Pipette method after digesting $10 \mathrm{~g}$ soil with $100 \mathrm{ml} \mathrm{H}_{2} \mathrm{O}_{2}$ and chemical dispersion using $\mathrm{Na}_{4} \mathrm{P}_{2} \mathrm{O}_{7}$ (Hartge and Horn, 1992).

\section{Data Analysis}

Analysis of variance (ANOVA) was performed using the generalized linear model procedure (GLM) of the software package SAS 9.2 (SAS Institute 2008) after checking for normality and homogeneity of variances. In the field study, nodulation parameters, shoot dry weight, $\mathrm{N}$ uptake, TGW, pod number, grain weight, protein content, and oil content were analyzed using the two-way ANOVA model below:

$$
Y_{i k l}=\mu+\alpha_{i}+\gamma_{k}+\alpha \gamma_{i k}+\beta_{l}+\delta_{l}+e_{i k l}
$$

where,

$$
\begin{aligned}
& Y_{i k l}=\text { responses (Yield, ...) } \\
& \mu=\text { intercept (overall mean response of all observations) } \\
& a_{i}=\text { the soybean cultivar effect (fixed effect) of the } i^{\text {th }} \\
& \text { level of } \alpha \\
& \gamma_{k}=\text { the Bradyrhizobium strain effect (fixed effect) of the } \\
& k^{\text {th }} \text { level of } \gamma \\
& \alpha \gamma_{i k}=\text { interaction effect of soybean cultivar by }
\end{aligned}
$$
Bradyrhizobium strains of the $i^{\text {th }}$ level of $\alpha$ with the $k^{\text {th }}$ level of $\gamma$

$\beta_{l}=$ the block effect (random effect) of the $l^{\text {th }}$ level of $\beta$

$\delta_{l}=$ the restriction error associated with the $t^{t h}$ block

$e_{i k l}=$ the random error

The same model was used to analyze the responses in greenhouse Experiments 1 and 2. However, the blocking effect was not considered in analyzing the responses in either greenhouse experiment. In greenhouse Experiment 1, soybean cultivar and Bradyrhizobium strain were considered fixed factors, whereas, in greenhouse Experiment 2, Bradyrhizobium strain and moisture regimes were modeled as fixed factors. All pairwise comparisons were performed using the Tukey-test $(p \leq 0.05)$. The effects of all factors and their interactions were assessed using the standard error of difference (mean SED).

\section{RESULTS}

\section{Shoot Biomass Yield}

In greenhouse experiment 1 , shoot dry weight was significantly influenced by soybean cultivar, Bradyrhizobium, and soybean cultivar $\times$ Bradyrhizobium interactions (Table 4). Across the five soybean cultivars, the shoot dry weight in cv. Shouna was on average higher than that in the other cultivars irrespective of Bradyrhizobium inoculation (Figure 1A). GMM36 inoculation consistently induced the highest significant shoot dry biomass. In greenhouse Experiment 2, shoot dry weight was significantly affected by moisture regime but not by Bradyrhizobium inoculation (Table 4). No significant interaction 
TABLE 4 | Summary of ANOVA for the influence of cultivar, bradyrhizobial type, moisture and their interrelations on nodulation and yield in the two greenhouse experiments and field trial.

\begin{tabular}{|c|c|c|c|c|c|c|c|c|c|c|}
\hline \multirow[t]{2}{*}{ Source } & \multicolumn{10}{|c|}{$p$-value } \\
\hline & df & Nodule no. & $\begin{array}{l}\text { Nodule dry } \\
\text { wt. (g) }\end{array}$ & $\begin{array}{c}\text { Biomass wt. } \\
\text { (g) }\end{array}$ & $\begin{array}{l}\text { Shoot } N \\
\left(g_{\text { kg }}^{-1}\right)\end{array}$ & TGW (g) & Pod no. & $\begin{array}{l}\text { Protein content } \\
\qquad\left(\mathrm{g} \mathrm{kg}^{-1}\right)\end{array}$ & $\begin{array}{l}\text { Oil content } \\
\left(\mathbf{g ~ k g}^{-1}\right)\end{array}$ & $\begin{array}{c}\text { Grain yield } \\
\left(\mathrm{kg} \mathrm{ha}^{-1}\right)\end{array}$ \\
\hline \multicolumn{11}{|c|}{ Greenhouse exp. 1} \\
\hline Cultivar (C) & 4 & $<0.001$ & $<0.001$ & $<0.001$ & 0.04 & ND & ND & ND & ND & ND \\
\hline Bradyrhizobia (B) & 3 & $<0.001$ & $<0.001$ & $<0.001$ & $<0.001$ & ND & ND & $N D$ & ND & ND \\
\hline $\mathrm{C} \times \mathrm{B}$ & 12 & $<0.001$ & $<0.001$ & $<0.001$ & 0.006 & ND & ND & ND & ND & ND \\
\hline \multicolumn{11}{|c|}{ Greenhouse exp. 2} \\
\hline Bradyrhizobia (B) & 4 & $<0.001$ & $<0.001$ & 0.20 & $<0.001$ & ND & ND & ND & ND & ND \\
\hline Moisture (M) & 1 & $<0.001$ & $<0.001$ & $<0.001$ & 0.14 & ND & ND & ND & ND & ND \\
\hline$B \times M$ & 4 & $<0.001$ & $<0.008$ & 0.46 & 0.21 & ND & ND & ND & ND & ND \\
\hline \multicolumn{11}{|l|}{ Field trial } \\
\hline Cultivar (C) & 2 & 0.51 & $<0.001$ & $<0.001$ & $<0.001$ & $<0.001$ & 0.02 & $<0.001$ & $<0.001$ & $<0.001$ \\
\hline Bradyrhizobia (B) & 4 & $<0.001$ & $<0.001$ & 0.23 & $<0.001$ & $<0.001$ & 0.009 & $<0.001$ & $<0.001$ & $<0.001$ \\
\hline $\mathrm{C} \times \mathrm{B}$ & 8 & 0.07 & $<0.001$ & 0.46 & 0.40 & $<0.001$ & 0.53 & 0.08 & 0.80 & $<0.001$ \\
\hline
\end{tabular}

p-value represents significant effects at the 5\% level. ANOVA, Analysis of variance; ND, Not determined.
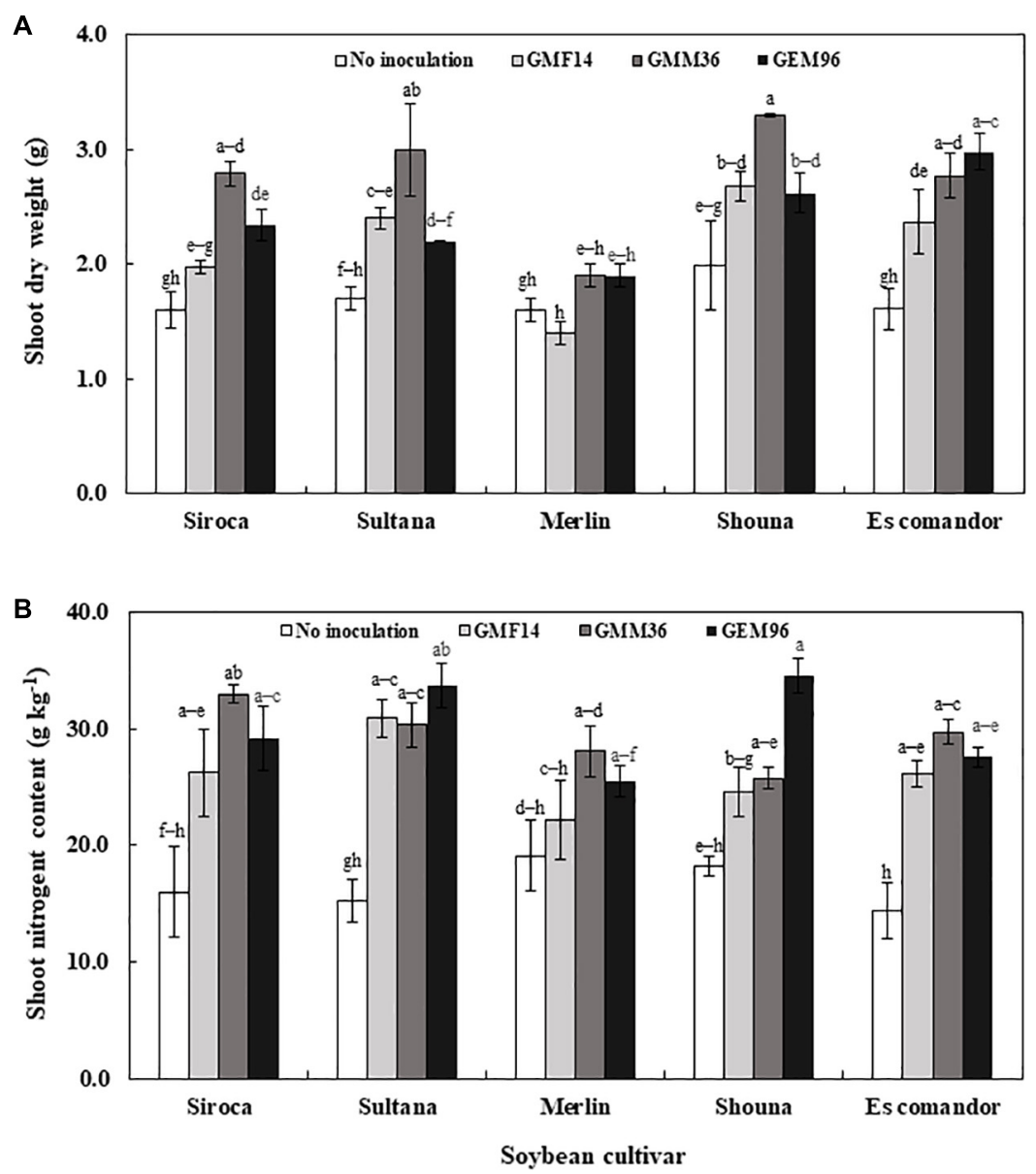

FIGURE 1 | Shoot dry weight (A) and shoot nitrogen content (B) following inoculation of different Bradyrhizobium strains to five soybean cultivars in the first greenhouse experiment. The error bars are standard deviation of three replications $(n=3)$. Values followed by the same letters on each bar are not significantly different at $p \leq 0.05$. 

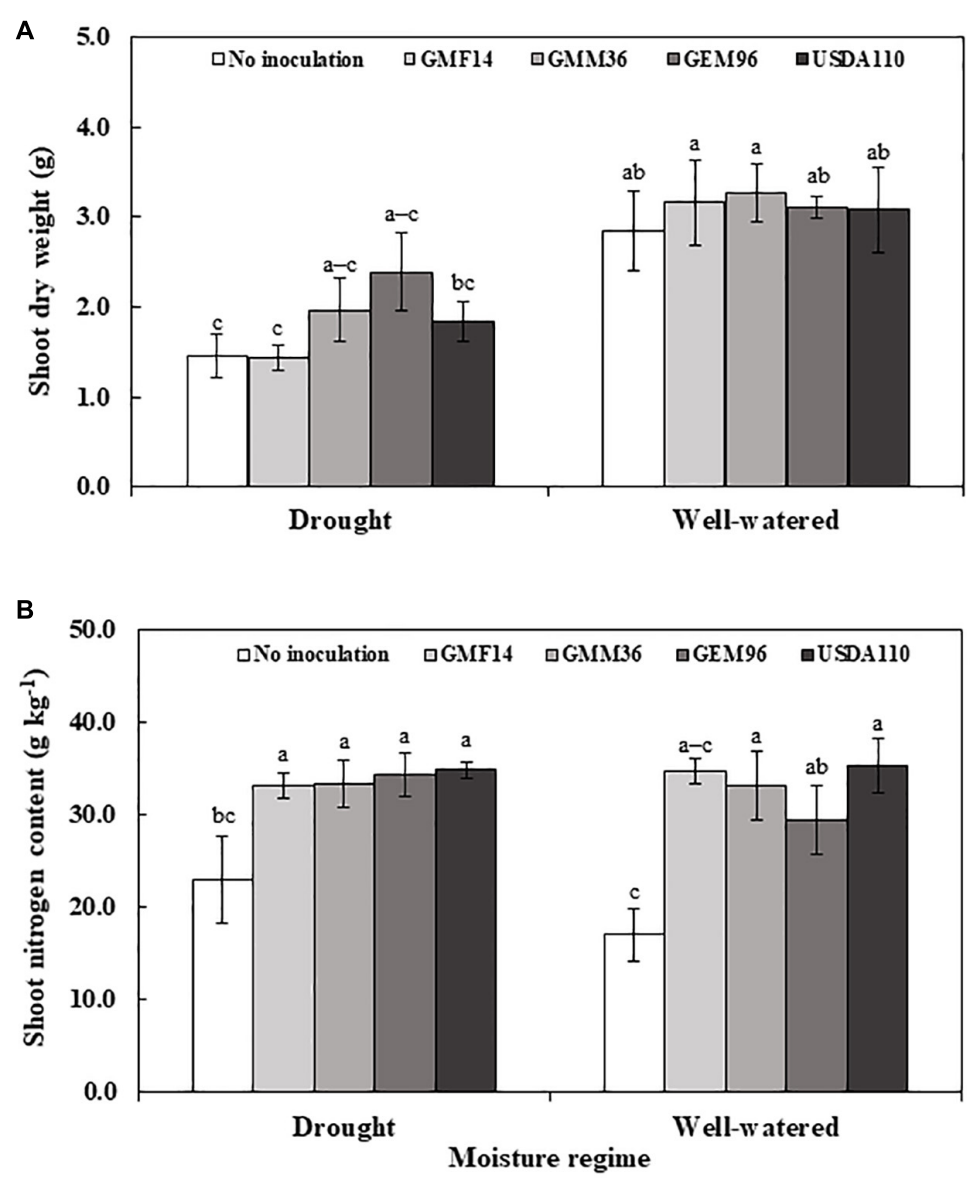

FIGURE 2 | Shoot dry weight (A) and shoot nitrogen content (B) of soybean plant (Cv. sultana) inoculated with different Bradyrhizobium strains in two moisture regimes in the second greenhouse experiment. The error bars are standard deviation of four replications $(n=4)$. Values followed by the same letters on each bar are not significantly different at $p \leq 0.05$.

was detected. The shoot dry weight under well-watered conditions was $70 \%$ higher compared to the drought conditions (Figure 2A and Supplementary Table 3). Under field conditions, soybean cultivar significantly affected shoot dry weight, but Bradyrhizobium inoculation did not influence shoot dry weight. No significant soybean variety $\times$ Bradyrhizobium interaction was detected. Independent of inoculation, Merlin showed the highest significant shoot dry weight of $3.92 \mathrm{t} \mathrm{ha}^{-1}$ (Figure 3A and Supplementary Table 4).

\section{Shoot N Uptake}

Shoot $\mathrm{N}$ content was significantly influenced by cultivar, Bradyrhizobium, and soybean cultivar $\times$ Bradyrhizobium interaction in greenhouse Experiment 1 (Table 4). Inoculation with GMM36 and GEM96 resulted in consistently higher shoot $\mathrm{N}$ contents (Figure 1B). GMM36 and GEM96 inoculation significantly increased the shoot $\mathrm{N}$ content by an average of $79 \%$ compared with the non-inoculated control. On average, $\mathrm{cv}$. Sultana (27.6 $\mathrm{g} \mathrm{kg}^{-1}$ ) and Siroca (26.1 $\mathrm{g} \mathrm{kg}^{-1}$ ) had the highest shoot $\mathrm{N}$ content, while the lowest was in Merlin (23.7 $\left.\mathrm{g} \mathrm{kg}^{-1}\right)$ irrespective of Bradyrhizobium inoculation.
In greenhouse Experiment 2, the shoot $\mathrm{N}$ content was significantly influenced by Bradyrhizobium inoculation but not by the moisture regime (Table 4). No significant interaction was detected. Inoculation increased the shoot $\mathrm{N}$ content by an average of $68 \%$ over non-inoculated control (Figure 2B and Supplementary Table 3). Under field conditions, the shoot $\mathrm{N}$ content was significantly influenced by the soybean cultivar and Bradyrhizobium inoculation (Table 4). Across the tested Bradyrhizobium strains and independent of soybean cultivar, inoculation with USDA110 and GEM96 induced the highest significant shoot $\mathrm{N}, 21.91$ and $21.89 \mathrm{~g} \mathrm{~kg}^{-1}$, respectively (Figure 3B). Shoot nitrogen increased by an average of 39\% between the inoculated and non-inoculated control under field conditions. Consistent with greenhouse Experiment 1, Sultana and Siroca significantly had the highest shoot $\mathrm{N}$ uptake (Supplementary Table 4).

\section{Nodulation}

Nodule number and nodule dry weights were significantly affected by cultivar, Bradyrhizobium strain, and soybean cultivar $\times$ Bradyrhizobium interaction in greenhouse Experiment 

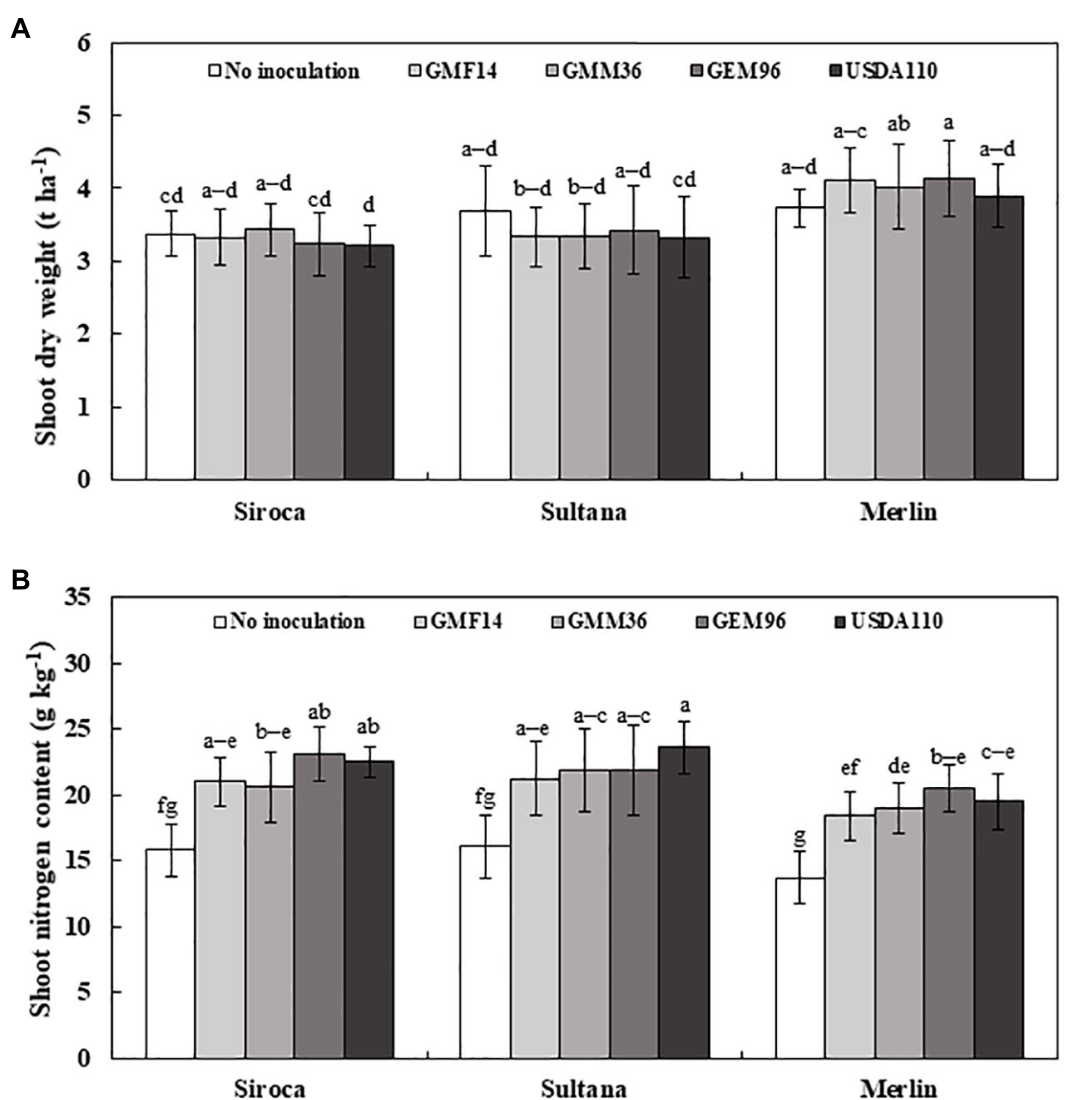

Soybean cultivar

FIGURE 3 | Shoot dry weight (A) and shoot nitrogen content (B) of three soybean cultivars inoculated with different Bradyrhizobium strains in field conditions. The error bars are standard deviation of six replications $(n=6)$. Values followed by the same letters on each bar are not significantly different at $p \leq 0.05$.

1 (Table 4). Consistently, low nodule number and nodule dry weights were observed when strains were inoculated to Merlin. Irrespective of soybean cultivar, inoculation with strains GMM36 and GEM96 induced a significantly higher average nodule number, 72 plant $^{-1}$ (Figure 4A). GMM36 inoculation resulted in the highest average nodule dry weight, $0.20 \mathrm{~g}$ (Figure 4B). A similar average number of nodules was observed in Siroca, Sultana, Shouna, and Comandor but was significantly higher than that in the Merlin group.

In greenhouse Experiment 2, Bradyrhizobium strain, moisture regime, and their interaction significantly influenced nodulation (Table 4). Consistently, a higher significant nodule number and nodule dry weights were observed in GMF14 and GMM36 inoculation under well-watered moisture conditions (Figure 5). However, under drought conditions, minimal differences in nodulation were observed among the Bradyrhizobium strains. There were 2-3 times higher nodule numbers and nodule dry weights in the well-watered conditions than in the drought conditions.

In the field experiment, Bradyrhizobium inoculation, soybean cultivar, and their interaction significantly affected nodule dry weight (Table 4). However, only the Bradyrhizobium strain significantly influenced the number of nodules formed. Regardless of soybean cultivar, inoculation with GEM96 resulted in a significant increase in nodule number $\left(18\right.$ plant $\left.^{-1}\right)$ and nodule dry weight $\left(0.08\right.$ g plant $\left.^{-1}\right)$ (Supplementary Table 4). The highest nodule number ( 21 plant $\left.^{-1}\right)$ and nodule dry weight (0.09 $\mathrm{g}$ plant $\left.^{-1}\right)$ were observed when Merlin was inoculated with GEM96 (Figure 6). In contrast to greenhouse Experiment 1, a similar number of nodules were observed among the three cultivars, although there were significantly heavier nodules on Siroca than on Sultana and Merlin.

\section{Pod Number and Grain Weight}

Pod number and TGW were significantly influenced by soybean cultivar and by Bradyrhizobium strain (Table 4). While the soybean cultivar $\times$ Bradyrhizobium strain interaction was significant for TGW, no significant differences were observed for pod number. Inoculation increased TGW and pod number by an average of 17 and 31\%, respectively, compared with noninoculated control (Table 5). Irrespective of soybean cultivar, TGW for the tested Bradyrhizobium isolates was in the order: USDA110 = GEM96 $\geq$ GMM36 $\geq$ GMF14 $>$ no inoculation. However, pod numbers did not differ statistically among the 

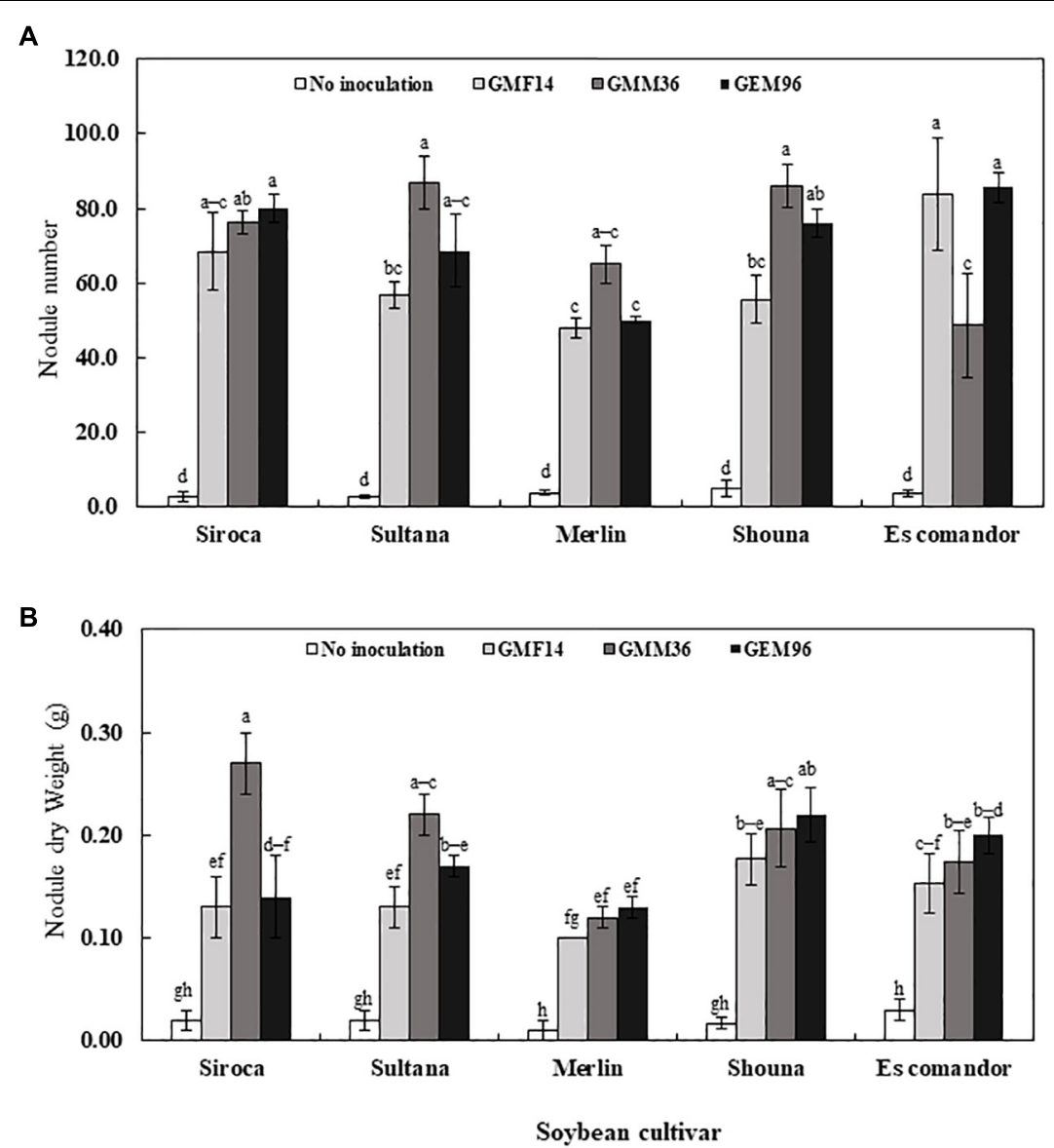

FIGURE 4 | Soybean nodule number (A) and nodule dry weight (B) following inoculation of different Bradyrhizobium strains to five soybean culuVars in the first greenhouse experiment. The error bars are standard deviation of three replications $(n=3)$. Values followed by the same letters on each bar are not significantly different at $p \leq 0.05$.

tested strains. Significantly higher TGW was observed in Siroca and Sultana independent of Bradyrhizobium inoculation. Inoculation significantly increased TGW in Siroca and Sultana but not in Merlin. The highest TGW of $148 \mathrm{~g}$ was reached in Siroca inoculated with USDA110. Soybean cultivars differed in pod number, with Sultana and Merlin showing significantly higher numbers than Siroca.

\section{Grain Yield}

Grain yield varied significantly among the soybean cultivars, Bradyrhizobium strains, and soybean cultivar $\times$ Bradyrhizobium interaction (Table 4). Generally, inoculation significantly increased grain yield by an average of $32 \%$ compared with the non-inoculated control. A significantly higher grain yield of 1.32 $\mathrm{t} \mathrm{ha}^{-1}$ was obtained in Sultana, while the lowest was obtained in Merlin (Table 5). Among the tested strains, inoculation with USDA110 and GEM96 significantly increased grain yield up to 1.40 and $1.38 \mathrm{t} \mathrm{ha}^{-1}$, respectively, while the lowest yield, $0.99 \mathrm{t} \mathrm{ha}^{-1}$ was observed in the non-inoculated control. A significantly higher grain yield, $1.47 \mathrm{t} \mathrm{ha}^{-1}$ was observed in Sultana in combination with USDA110 and was statistically similar to Sultana-GMM36, Siroca-GEM96, Siroca-USDA110, Sultana-GEM96, and Merlin-USDA110. The lowest grain yield was observed in non-inoculated Merlin.

\section{Protein and Oil Content}

Protein and oil contents were significantly influenced by soybean cultivar and Bradyrhizobium strain inoculation (Table 4). No significant soybean cultivar $\times$ Bradyrhizobium interactions were detected for the protein and oil contents. Soybean cultivars differed in protein content, with Siroca yielding significantly more protein content $\left(407 \mathrm{~g} \mathrm{~kg}^{-1}\right)$ irrespective of Bradyrhizobium inoculation (Table 5). Generally, the protein content in grains increased by an average of $24 \%$ compared with the non-inoculated control. Among the tested strains, inoculation with GEM96 resulted in a significantly higher protein content of $412 \mathrm{~g} \mathrm{~kg}^{-1}$ and was statistically similar to USDA110 and GMF14. Sultana and Merlin had the highest significant oil contents, 230 and $228 \mathrm{~g} \mathrm{~kg}^{-1}$, respectively. In contrast to the protein content, the non-inoculated control yielded the highest oil content, $254 \mathrm{~g} \mathrm{~kg}^{-1}$, while the lowest oil content was observed in GEM96. 

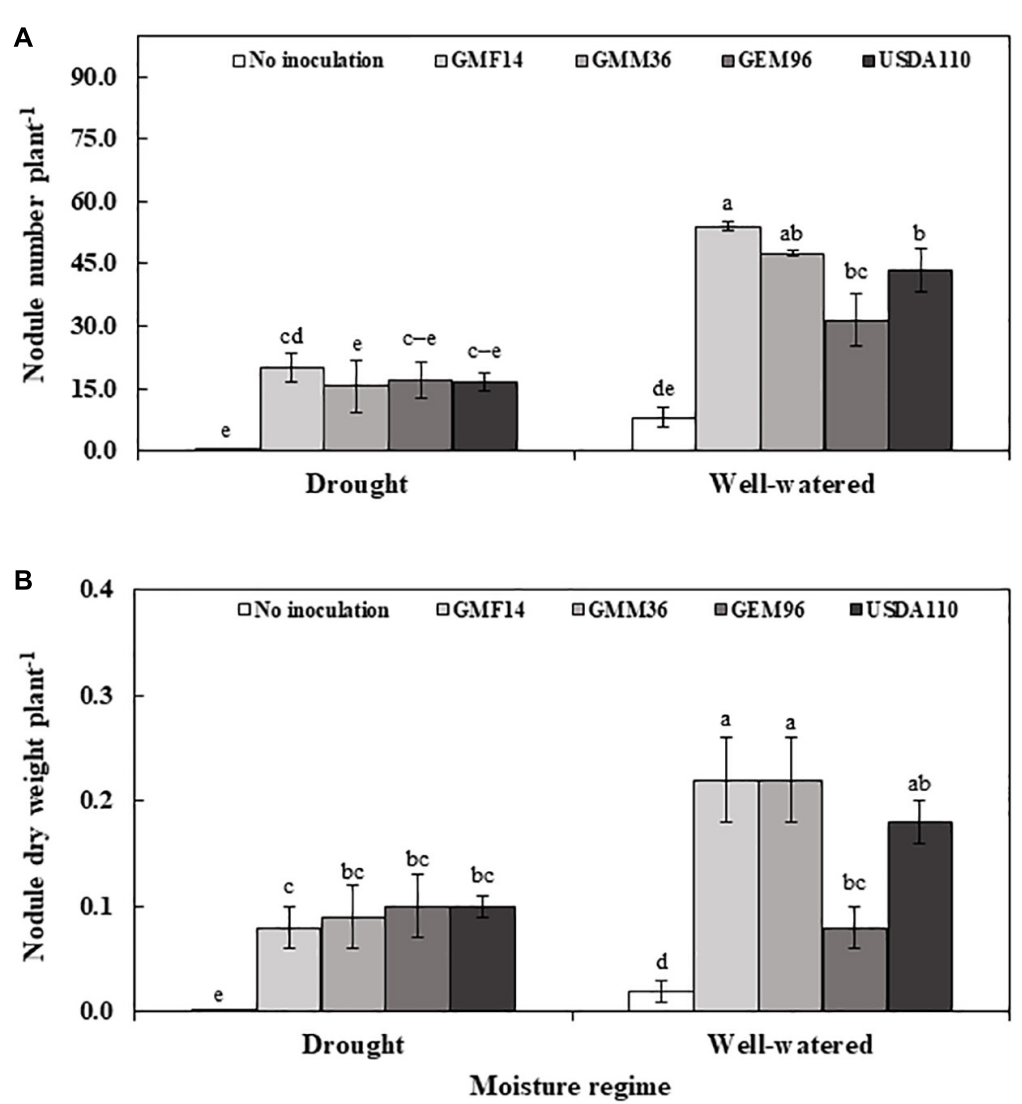

FIGURE 5 | Nodule number (A) and nodule dry weight (B) of soybean plant inoculated with different Bradyrhizobium strains in two moisture regimes in the second greenhouse experiment. The error bars are standard deviation of four replications $(n=4)$. Values followed by the same letters on each bar are not significantly different at $P \leq 0.05$.

\section{DISCUSSION}

\section{Nodulation and N Uptake in Greenhouse and Field Conditions}

The soils for both greenhouse experiments were collected from the same site where the field trial was conducted. However, significantly higher nodulation and shoot $\mathrm{N}$ uptake were observed in the greenhouse compared with the field conditions, indicating the strong influence of abiotic variables on nodulation and soybean growth (Hungria and Vargas, 2000; Goyal et al., 2021). The observed low mean temperature $\left(11.4^{\circ} \mathrm{C}\right)$ in field conditions in early May translated into a low root zone temperature (Schmidt et al., 2015), and low precipitation (5 mm, i.e., only $20 \%$ of total precipitation) during germination and seedling establishment of soybean plants likely influenced the symbiotic performance of the strains. This potentially impacted nodulation and resulted in a substantial reduction in biologically derived N (Márquez-García et al., 2015). Thus, early drought and low temperature are important factors in regard to efficient $\mathrm{N}$ fixation and enhancement of soybean productivity traits. Other studies have reported induced nodule senescence, reduced leghemoglobin content, and BNF in leguminous plants grown under drought conditions compared with their counterparts in well-watered soils (Ruiz-Lozano et al., 2001; Márquez-García et al., 2015; Kibido et al., 2020). As expected, the moisture regime influenced the shoot biomass increase but did not correspond with $\mathrm{N}$ uptake, likely as a result of the dilution effect due to the higher dry matter accumulation in the well-watered conditions (Jarrell and Beverly, 1981).

We observed 2-4 times more nodules in both greenhouse experiments compared with the field trial, which corresponded with over three times higher soybean shoot $\mathrm{N}$ uptake. Nodule numbers in both greenhouse experiments were within the range of values reported for sites with a soybean-growing history in Muncheberg and Fehrow, Northeast Germany (Halwani et al., 2021) and Central Germany (Zimmer et al., 2016). These values are, however, lower than those in a report that used metadata involving numerous field trials in several countries and climates (Thilakarathna and Raizada, 2017), re-echoing low soybean-rhizobium symbiosis in the Northeastern agro-climatic environment of Germany.

\section{Nodulation Response of Strains to Stressed Conditions}

Our results showed that the present indigenous Bradyrhizobium strains from Northeast Germany were able to nodulate a range 

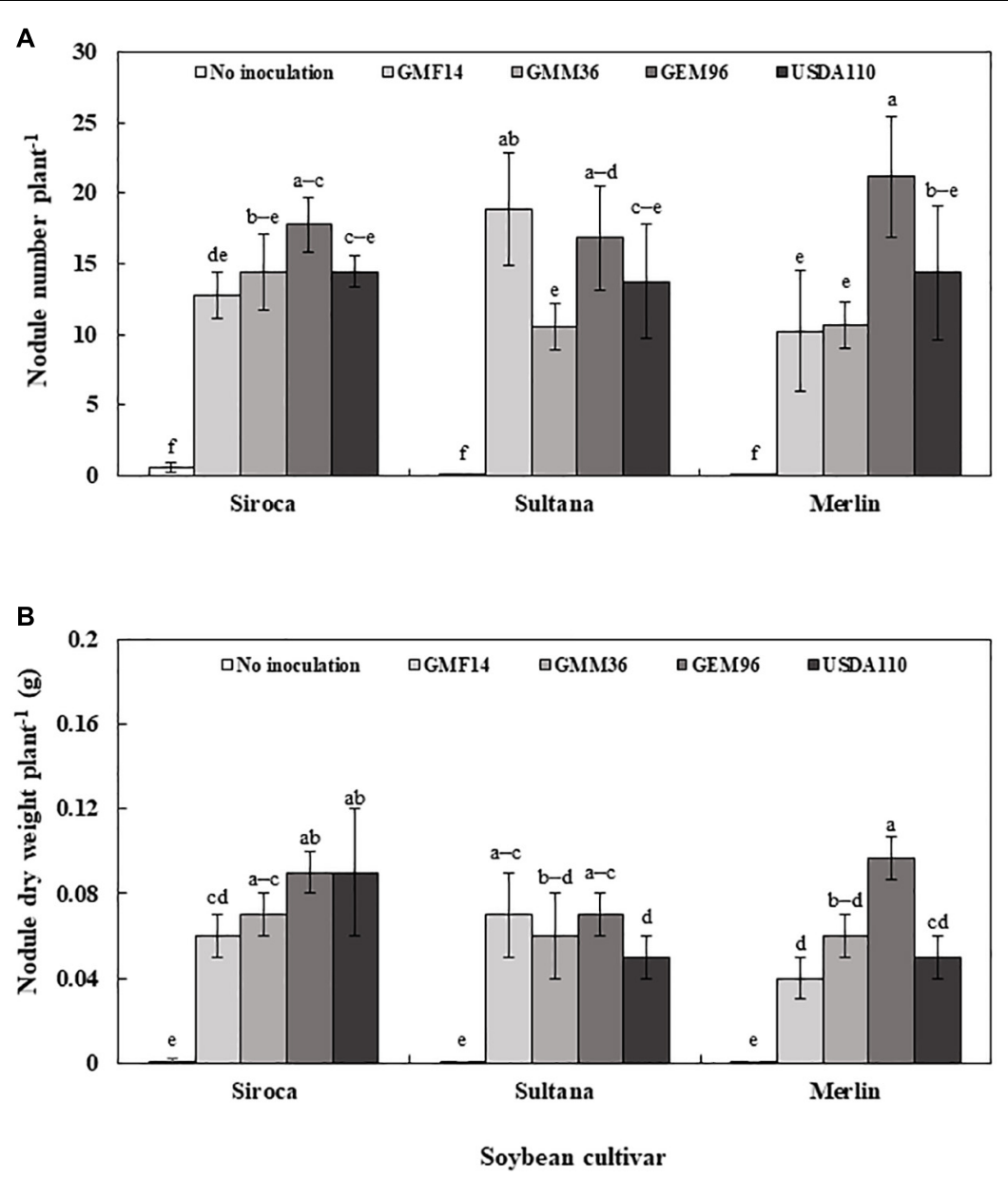

FIGURE 6 | Nodule number (A) and Nodule dry weight (B) of three soybean culuVars inoculated with different Bradyrhizobium strains in field conditions. The error bars are standard deviation of six replications $(n=6)$. Values followed by the same letters on each bar are not significantly different at $p \leq 0.05$.

of soybean cultivars adapted to Central European conditions. The significant strain $\times$ cultivar interaction in most measured parameters suggests greater specificity, in agreement with Mason et al. (2021), who reported that all indigenous isolates from the Philippines were able to form nodules on almost all soyean cultivars.

The performance of the strains, however, varied based on their combination with specific soybean cultivars under different soil moisture conditions. While inoculation of Merlin, in general, showed low nodulation and biomass yield under normal moisture conditions, there was enhanced nodulation with GEM96 under field conditions with drought stress. The superior effects of GEM96 were minimal when inoculated to Sultana in greenhouse conditions, implying a better symbiotic relationship of Merlin with GEM96 in drought agro-climates. Yuan et al. (2020), in agreement with our results, observed that cold-tolerant GMF14 strain inoculation to Merlin yielded the highest biomass growth under low-temperature conditions. Other reports also observed higher potentials for rhizobium symbiosis, nodulation, and BNF among local cultivars than in breeding lines (Provorov and Tikhonovich, 2003; Kouas et al., 2005; Rodiño et al., 2011). These results imply that the symbiotic performance of Merlin, a cultivar well adapted to the growing conditions in Northeast Germany (Karges et al., 2022), could be enhanced under drought conditions by inoculation with GEM96.

The tolerance of rhizobium strains to drought reflects their ability to remain viable in the soil and is linked to the genetic traits that affect BNF, nodulation, survival, growth rate, and specificity with the host plant (Zaman-Allah et al., 2007). Their efficiency in colonizing roots likely contributes to executing beneficial plant growth-promoting activities (Kibido et al., 2020). On the other hand, the ability of the host plant to enhance BNF under drought conditions is linked to its sustained supply of photosynthates to the nodules (King and Purcell, 2005). Thus, a combination of these traits could be essential to mitigate the effects of drought.

The observed cultivar-by-strain interaction in varying soil moisture conditions reflects the impacts of the environment wherein the strains were isolated and thus presents opportunities to harness cultivar-Bradyrhizobium specificity for enhanced soybean productivity (Gunnabo et al., 2019). According to Giller (2001) and Grossman et al. (2011), the impacts of the 
TABLE 5 | Effects of different Bradyrhizobium strains inoculated to three soybean cultivars and their interaction on grain yield, pod number, protein yield, and thousand-grain weight under field conditions.

\begin{tabular}{|c|c|c|c|c|c|c|}
\hline Average values & & Pod no. & TGW (g) & Protein content $\left(\mathbf{g ~ k g}^{-1}\right)$ & Oil content (g kg $\left.{ }^{-1}\right)$ & Grain yield (t ha $\left.{ }^{-1}\right)$ \\
\hline \multicolumn{7}{|l|}{ Cultivar } \\
\hline Siroca & & $14 \mathrm{~b}$ & $128 \mathrm{a}$ & $407 a$ & $216 b$ & $1.27 \mathrm{~b}$ \\
\hline Sultana & & $17 \mathrm{a}$ & $130 \mathrm{a}$ & $379 b$ & $230 \mathrm{a}$ & $1.32 \mathrm{a}$ \\
\hline Merlin & & $15 \mathrm{ab}$ & $107 \mathrm{~b}$ & $378 b$ & 228 a & $1.12 \mathrm{c}$ \\
\hline Mean SED $(p=0.05)$ & & 1.8 & 5.9 & 9.21 & 7.62 & 0.04 \\
\hline \multicolumn{7}{|l|}{ Bradyrhizobia } \\
\hline No inoculation & & $12 \mathrm{c}$ & $107 \mathrm{c}$ & $326 \mathrm{c}$ & $254 a$ & $0.99 d$ \\
\hline GMF14 & & $15 \mathrm{ab}$ & $117 b$ & $403 \mathrm{ab}$ & $216 \mathrm{bc}$ & $1.20 c$ \\
\hline GMM36 & & $15 a b$ & $125 a b$ & 391 b & $225 \mathrm{~b}$ & $1.25 c$ \\
\hline GEM96 & & $16 \mathrm{a}$ & $128 \mathrm{a}$ & $412 \mathrm{a}$ & $213 c$ & $1.38 a b$ \\
\hline USDA110 & & $17 \mathrm{a}$ & $131 \mathrm{a}$ & $408 \mathrm{a}$ & $214 \mathrm{bc}$ & $1.40 \mathrm{a}$ \\
\hline Mean SED $(p=0.05)$ & & 2.8 & 9.0 & 13.90 & 11.51 & 0.07 \\
\hline Cultivar & Bradyrhizobia & & & & & \\
\hline \multirow[t]{5}{*}{ Siroca } & No inoculation & 13 & 110 de & 345 & 244 & $0.99 f g$ \\
\hline & GMF14 & 14 & 118 cde & 415 & 209 & $1.23 \mathrm{cde}$ \\
\hline & GMM36 & 15 & 128 bcd & 413 & 213 & $1.26 \mathrm{bcd}$ \\
\hline & GEM96 & 16 & $135 \mathrm{abc}$ & 426 & 208 & $1.43 a$ \\
\hline & USDA110 & 14 & $148 \mathrm{a}$ & 435 & 206 & $1.41 a b$ \\
\hline \multirow[t]{5}{*}{ Sultana } & No inoculation & 15 & 110 de & 310 & 263 & $1.08 \mathrm{ef}$ \\
\hline & GMF14 & 17 & 127 bcd & 400 & 221 & $1.24 \mathrm{~cd}$ \\
\hline & GMM36 & 17 & $143 \mathrm{ab}$ & 385 & 232 & $1.45 a$ \\
\hline & GEM96 & 16 & $135 \mathrm{abc}$ & 399 & 220 & $1.32 \mathrm{abc}$ \\
\hline & USDA110 & 18 & 133 abc & 403 & 215 & $1.47 \mathrm{a}$ \\
\hline \multirow[t]{5}{*}{ Merlin } & No inoculation & 12 & $101 \mathrm{e}$ & 322 & 256 & $0.89 \mathrm{~g}$ \\
\hline & GMF14 & 16 & 107 e & 395 & 219 & 1.12def \\
\hline & GMM36 & 15 & 104 e & 376 & 231 & $1.06 f$ \\
\hline & GEM96 & 17 & 112 de & 411 & 211 & $1.23 \mathrm{cde}$ \\
\hline & USDA110 & 19 & 112 de & 386 & 222 & $1.33 a b c$ \\
\hline Mean SED $(p=0.05)$ & & - & 19.5 & - & - & 0.15 \\
\hline
\end{tabular}

Values followed by the same letter(s) in each column are not significantly different at $p \leq 0.05$. TGW, Thousand-grain weight; SED, Standard Error of a Difference.

environment, management, and soil edaphic features could influence the environmental resiliency of strains to nodulate in extreme conditions. Strains GEM96 and GMM36 were isolated from a drought-prone arable field in Müncheberg, while GMF14 was isolated in Fehrow with a similar agroclimate but under varying management practices. Thus, micro conditions at the field scale likely influenced the adaptive abilities of the strains. This implies that the strains newly introduced by inoculation with commercial inoculants could survive and remain viable in the soil, and their interaction with the immediate environment is likely to enhance stressinduced genetic changes which would be relevant for their adaptation. A report by Zhang et al. (2003), similar to our observations, showed that rhizobium isolates from a northernadapted climate were more effective under cool conditions. Numerous biotic and abiotic factors, such as $\mathrm{N}$ limitation and drought stress, have been postulated to be important factors that affect the symbiotic performance of persisting rhizobium strains previously introduced to the soil by inoculation (Squartini et al., 1993; Bordeleau and Prévost, 1994; Bano et al., 2010; Thilakarathna and Raizada, 2017).
Although nodulation parameters and biomass yield are important traits for assessing host-rhizobium performance (Voisin et al., 2003), we did not analyze other important plant metabolites, such as coumestrol, abscisic acid, reactive oxygen species, and nitrogenase activity, which are produced or altered in response to drought (Wilkinson and Davies, 2009; Tripathi et al., 2016). Future research should include important bioassays that may be necessary to explain the efficiency of this plantrhizobium interaction.

\section{Symbiotic Effectiveness of Local Isolates Compared With Standard Strain Under Field Conditions and Their Compatibility With Soybean Cultivars}

The present study confirms the importance of inoculation for enhanced soybean yield in Europe (Albareda et al., 2009; Zimmer et al., 2016; Halwani et al., 2021). Altogether, inoculation with our isolates significantly increased the protein content, grain yield, TGW, and pod number up to an average of 24, 32, 17, and 31\%, respectively. Zimmer et al. (2016) observed 
similar protein contents and twice higher grain yield values using commercial inoculants in Central Germany. The grain yield, TGW, and pod number were positively correlated with nodule number and nodule dry weight at the R3 growth stage. This observation confirms many previous reports that enhanced nodulation is essential for increased soybean grain yield (Albareda et al., 2009; Thilakarathna and Raizada, 2017; Moretti et al., 2018).

In the sampled sites, commercial HiStick ${ }^{\circledR}$-soy inoculum containing high $\mathrm{N}_{2}$ fixing $B$. japonicum was introduced between 2013 and 2017 (Zimmer et al., 2016; Yuan et al., 2020). Thus, our isolates that show similarity with strains in commercial inoculants may have benefitted from the horizontal transfer of symbiotic genes from commercial inoculants (Zimmer et al., 2016; Yuan et al., 2020). Horizontal gene transfer is an adaptation mechanism in bacteria and may occur within several years after introducing commercial inoculants (Barcellos et al., 2007; Soucy et al., 2015). Strain GEM96 was isolated from a site with no soybean history but was cultivated with uninoculated alfalfa in the past.

Strain GEM96, GMF14, and USDA110 inoculation yielded acceptable protein contents (403-412 $\mathrm{g} \mathrm{kg}^{-1}$ ) for human consumption and were within the range reported for early maturity soybean groups in Austria (Vollmann et al., 2000). The highest grain yield was achieved by the Sultana-USDA110, Sultana-GMM36, and Siroca-GEM96 combinations. This significant strain $\times$ cultivar interaction suggests the need to match certain cultivars with specific strains to improve soybean yield. Therefore, inoculation of GEM96 to Siroca or Sultana presents an option to increase soybean grain yield in Northeast Germany. The symbiotic relationship of Merlin with GEM96 for biomass production did not translate into increased grain yield, likely as a result of limited rainfall during the reproductive growth stage of soybean plants.

The observed yield in the present study was lower than the average reported by Reckling et al. (2020) in 16 monitored farm trials in northeastern Germany during the 2014-2016 growing year. This is ascribed to the drought conditions, which particularly marred the optimum growth of soybean plants. The annual precipitation in the trial year was 440 $\mathrm{mm}$, and the cumulative rainfall amount during the critical growth of soybean (May-August) was only $164 \mathrm{~mm}$, a level short of $90 \mathrm{~mm}$ compared with the average in the last 20 years (Supplementary Table 2). In this regard, even though the present isolates may possess the ability to thrive under drought and cold stress conditions, this trait may only be relevant immediately after sowing or seedling establishment, where an adequate rhizobium population is necessary for successful inoculation (Albareda et al., 2009; Grossman et al., 2011; Chibeba et al., 2018). This indicates that even after successful inoculation, adequate rainfall would be required to obtain optimum crop yield. Thus, further experiments under well-watered conditions are required to evaluate the optimal symbiotic capabilities of the strains. Zimmer et al. (2016) showed that successful soybean cultivation in Europe depends on effective inoculation with non-native Bradyrhizobium. Our present study, which agrees with Yuan et al. (2020), demonstrated that there are promising indigenous Bradyrhizobium strains that are tolerant to cold temperatures and drought and could potentially be employed to increase soybean BNF and yield in Central Europe. Our results also suggest the need to explore other areas in Europe with longer field-grown inoculated soybean cultivation histories to identify more adapted Bradyrhizobium symbionts to expand the pool of inoculum resources in Europe.

\section{CONCLUSION}

Inoculation of soybean with the present isolates induced higher nodulation, which increased grain yield and protein content compared with the uninoculated control. In particular, the symbiotic performance of the isolates varied based on their combination with specific soybean cultivars under drought and well-watered conditions. There was consistently high nodulation and improved biomass growth in MerlinGEM96 inoculation in drought conditions but not in well-watered conditions. This, however, did not translate into increased grain yield at harvest. Strain GEM96 inoculation consistently enhanced yield attributes and its combination with Siroca or Sultana resulted in increased grain yield to a similar extent as the standard USDA110 strain. Thus, GEM96 in combination with Siroca or Sultana is effective for grain production under drought-growing conditions in Northeast Germany.

\section{DATA AVAILABILITY STATEMENT}

The original contributions presented in the study are included in the article/Supplementary Material, further inquiries can be directed to the corresponding author/s.

\section{AUTHOR CONTRIBUTIONS}

RO, KY, KA, and MR conceived and performed the experiments. RO performed all the analyses and wrote the manuscript with assistance from $\mathrm{MH}, \mathrm{DE}, \mathrm{NO}-\mathrm{O}$, and $\mathrm{SB}-\mathrm{K}$ coordinated the transportation of isolates, and analysis, and provided insightful input into the manuscript write-up. All authors contributed to writing the final version of the manuscript.

\section{FUNDING}

This work was financed by the SusCrop-ERA-NET project LegumeGap (Grant No. 031B0807B) and the Innovation Network to Improve Soybean Production under the Global Change (INNISOY) through the European Interest Group CONCERT-Japan (Grant No. 01DR17011A). MR was funded by the Deutsche Forschungsgemeinschaft (DFG, German Research Foundation) (Grant No. 420661662). 


\section{ACKNOWLEDGMENTS}

We thank Gunhild Rosner, colleagues at Research Area 1 (PB1), and all staff at the ZALF research station in Müncheberg for their assistance throughout the study.

\section{REFERENCES}

Albareda, M., Rodríguez-Navarro, D. N., and Temprano, F. J. (2009). Soybean inoculation: dose, $\mathrm{N}$ fertilizer supplementation and rhizobia persistence in soil. Field Crop Res. 113, 352-356. doi: 10.1016/j.fcr.2009.05.013

Bano, A., Batool, R., and Dazzo, F. (2010). Adaptation of chickpea to desiccation stress is enhanced by symbiotic rhizobia. Symbiosis 50, 129-133. doi: 10.1007/ s13199-010-0051-9

Barcellos, F. G., Menna, P., da Silva Batista, J. S., and Hungria, M. (2007). Evidence of horizontal transfer of symbiotic genes from a Bradyrhizobium japonicum inoculant strain to indigenous diazotrophs Sinorhizobium (Ensifer) fredii and Bradyrhizobium elkanii in a Brazilian Savannah soil. Appl. Environ. Microbiol. 73, 2635-2643. doi: 10.1128/AEM.01823-06

Bordeleau, L. M., and Prévost, D. (1994). Nodulation and nitrogen fixation in extreme environments. Plant Soil 161, 115-125. doi: 10.1007/978-94-011-1088$4 \_13$

Cernay, C., Ben-Ari, T., Pelzer, E., Meynard, J. M., and Makowski, D. (2015). Estimating variability in grain legume yields across Europe and the Americas. Sci. Rep. 5:11171. doi: 10.1038/srep11171

Chibeba, A. M., Kyei-Boahen, S., Guimaraes, M. F., Nogueira, M. A., and Hungria, M. (2018). Feasibility of transference of inoculation-related technologies: a case study of evaluation of soybean rhizobial strains under the agro-climatic conditions of Brazil and Mozambique. Agric. Ecosyst. Environ. 261, 230-240. doi: 10.1016/j.agee.2017.06.037

Choudhury, A. T. M. A., and Kennedy, I. R. (2004). Prospects and potentials for systems of biological nitrogen fixation in sustainable rice production. Biol. Fertility Soils 39, 219-227. doi: 10.1007/s00374-003-0706-2

de Visser, C. L. M., Schreuder, R., and Stoddard, F. (2014). The EU's dependency on soya bean import for the animal feed industry and potential for EU produced alternatives. Ocl 21:D407.

Egamberdieva, D., Li, L., Ma, H., Wirth, S., and Bellingrath-Kimura, S. D. (2019). Soil amendment with different maize biochars improves chickpea growth under different moisture levels by improving symbiotic performance with mesorhizobium ciceri and soil biochemical properties to varying degrees. Front. Microbiol. 10:2423. doi: 10.3389/fmicb.2019.02423

Feng, L., Wang, H., Ma, X., Peng, H., and Shan, J. (2021). Modeling the current land suitability and future dynamics of global soybean cultivation under climate change scenarios. Field Crops Res. 263:108069. doi: 10.1016/j.fcr.2021.108069

Giller, K. E. (2001). Nitrogen Fixation in Tropical Cropping Systems, 2nd Edn. Wallingford: CABI publishing, CABI International.

Goyal, R. K., Mattoo, A. K., and Schmidt, M. A. (2021). Rhizobial-Host interactions and symbiotic nitrogen fixation in legume crops toward agriculture sustainability. Front. Microbiol. 12:669404. doi: 10.3389/fmicb.2021.669404

Grossman, J. M., Schipanski, M. E., Sooksanguan, T., Seehaver, S., and Drinkwater, L. E. (2011). Diversity of rhizobia in soybean [Glycine max (Vinton)] nodules varies under organic and conventional management. Appl. Soil Ecol. 50, 14-20. doi: 10.1016/j.apsoil.2011.08.003

Gunnabo, A. H., Geurts, R., Wolde-meskel, E., Degefu, T., Giller, K. E., and van Heerwaarden, J. (2019). Genetic interaction studies reveal superior performance of Rhizobium tropici CIAT899 on a range of diverse East African common bean (Phaseolus vulgaris L.) genotypes. Appl. Environ. Microbiol. 85:e01763-19. doi: 10.1128/AEM.01763-19

Halwani, M., Reckling, M., Egamberdieva, D., Omari, R. A., Sonoko, D. B., Bachinger, J., et al. (2021). Soybean nodulation response to cropping interval and inoculation in European cropping systems. Front. Plant Sci. 12:638452. doi: $10.3389 /$ fpls.2021.638452

Hartge, K. H., and Horn, R. (1992). Die Physikalische Untersuchung von Böden (In German.), 3rd Edn. Stuttgart: Ferdinand Enke.

Hufnagel, J., Reckling, M., and Ewert, F. (2020). Diverse approaches to crop diversification in agricultural research. A review. Agron. Sustain. Dev. 40:14.

\section{SUPPLEMENTARY MATERIAL}

The Supplementary Material for this article can be found online at: https://www.frontiersin.org/articles/10.3389/fpls.2021. 707080/full\#supplementary-material

Hungria, M., and Vargas, M. A. T. (2000). Environmental factors affecting $\mathrm{N}_{2}$ fixation in grain legumes in the tropics, with an emphasis on Brazil. Field Crops Res. 65, 151-164. doi: 10.1016/s0378-4290(99)00084-2

Jarrell, W. M., and Beverly, R. B. (1981). The dilution effect in plant nutrition studies. Adv. Agron. 34, 197-224. doi: 10.1016/s0065-2113(08)60887-1

Kadiata, B. D., Schubert, S., and Yan, F. (2012). Assessment of different inoculants of Bradyrhizobium japonicum on nodulation, potential $\mathrm{N}_{2}$ fixation and yield performance of soybean (Glycine max L.). J. Anim. Plant Sci. 13, 1704-1713.

Karges, K., Bellingrath-Kimura, S. D., Watson, C. A., Stoddard, F. L., Halwani, M., and Reckling, M. (2022). Agro-economic prospects for expanding soybean production beyond its current northerly limit in Europe. Eur. J. Agron. 133:126415. doi: 10.1016/j.eja.2021.126415

Kibido, T., Kunert, K., Makgopa, M., Greve, M., and Vorster, J. (2020). Improvement of rhizobium- soybean symbiosis and nitrogen fixation under drought. Food Energy Security 9:e177. doi: 10.1002/fes3.177

King, C. A., and Purcell, L. C. (2005). Inhibition of $\mathrm{N}_{2}$ fixation in soybean is associated with elevated ureides and amino acids. Plant Physiol. 137, 1389-1396. doi: $10.1104 /$ pp.104.056317

Kouas, S., Labidi, N., Debez, A., and Abdelly, C. (2005). Effect of P on nodule formation and N fixation in bean. Agron. Sustain. Dev. 25, 389-393.

Krautgartner, R., Lefebvre, L., Rehder, L. E., Boshnakova, M., Dobrescu, M., Flach, B., et al. (2018). EU-28 Oilseeds and Products Annual. Washington, DC: USDA Foreign Agricultural Service (FAS).

Laranjo, M., and Oliveira, S. (2011). Tolerance of mesorhizobium type strains to different environmental stresses. Antonie Van Leeuwenhoek 99, 651-662. doi: 10.1007/s10482-010-9539-9

Márquez-García, B., Shaw, D., Cooper, J. W., Karpinska, B., Quain, M. D., Makgopa, E. M., et al. (2015). Redox markers for drought-induced nodule senescence, a process occurring after drought-induced senescence of the lowest leaves in soybean (Glycine max Merr.). Ann. Bot. 116, 497-510. doi: 10.1093/ $\mathrm{aob} / \mathrm{mcv} 030$

Mason, M. L. T., De Guzman, B. L. T., Yamamoto, A., and Saeki, Y. (2021). Symbiotic performance of indigenous soybean bradyrhizobia from the Philippines with soybean (Glycine max [L.] Merill) cultivars harboring different Rj genotypes. Symbiosis 83, 55-63. doi: 10.1007/s13199-020-00731-7

Moretti, L. G., Lazarini, E., Bossolani, J. W., Parente, T. L., Caioni, S., Araujo, R. S. et al. (2018). Can additional inoculations increase soybean nodulation and grain yield? Agron. J. 110, 715-721. doi: 10.1007/s11274-019-2752-4

Provorov, N. A., and Tikhonovich, I. A. (2003). Genetic resources for improving nitrogen fixation in legume-rhizobia symbiosis. Genet. Resour. Crop Evol. 50, 89-99. doi: 10.3389/fmicb.2018.02105

Rahmani, A. H., Saleh-rastin, N., Khavazi, K., Asgharzadeh, A., Fewer, D., Kiani, S., et al. (2008). Selection of thermotolerant bradyrhizobial strains for nodulation of soybean (Glycine max L.) in semi-arid regions of Iran. World J. Microbiol. Biotechnol. 25, 591-600. doi: 10.1007/s11274-008-9927-8

Reckling, M., Bergkvist, G., Watson, C. A., Stoddard, F. L., and Bachinger, J. (2020). Re-designing organic grain legume cropping systems using systems agronomy. Eur. J. Agron. 112:125951. doi: 10.1016/j.eja.2019.125951

Reckling, M., Doring, T. F., Bergkvist, G., Stoddard, F. L., Watson, C. A., Seddig, S., et al. (2018). Grain legume yields are as stable as other spring crops in long-term experiments across northern Europe. Agron. Sustain. Dev. 38:63. doi: 10.1007/s13593-018-0541-3

Rodiño, A. P., De La Fuente, M., De Ron, A. M., Lema, M. J., Drevon, J. J., and Santalla, M. (2011). Variation for nodulation and plant yield of common bean genotypes and environmental effects on the genotype expression. Plant Soil 346, 349-361. doi: 10.1007/s11104-011-0823-x

Ruiz-Lozano, J. M., Collados, C., Barea, J., and Azcón, M. R. (2001). Arbuscular mycorrhizal symbiosis can alleviate drought-induced nodule senescence in soybean plants. New Phytol. 151, 493-502. doi: 10.1046/j.0028-646x.2001. 00196.x 
Schmidt, J., Messmer, M., and Wilbois, K.-P. (2015). Beneficial microorganisms for soybean (Glycine max (L.) Merr), with a focus on low root-zone temperatures. Plant Soil 397, 411-445. doi: 10.1007/s11104-015-2546-x

Sims, J. T. (2009). "Soil test phosphorus: principles and methods," in Methods of Phosphorus Analysis for Soils, Sediments, Residuals and Waters Southern Cooperative Series Bulletin No. 408, 2nd Edn, eds J. L. Kovar and G. M. Pierzynski (Blacksburg, VA: Virginia Tech University), 9-19.

Soucy, S. M., Huang, J., and Gogarten, J. P. (2015). Horizontal gene transfer: building the web of life. Nat. Rev. Genet. 16, 472-482. doi: 10.1038/nrg3962

Squartini, A., Dazzo, B. F., Casella, S., and Nuti, P. M. (1993). The root nodule symbiosis between Rhizobium 'hedysari' and its drought-tolerant host Hedysarum coronarium. Symbiosis 15, 227-238.

Thilakarathna, M. S., and Raizada, M. N. (2017). A meta-analysis of the effectiveness of diverse rhizobia inoculants on soybean traits under field conditions. Soil Biol. Biochem. 105, 177-196. doi: 10.1016/j.soilbio.2016.11.022

Tripathi, P., Rabara, R. C., Reese, R. N., Miller, M. A., Rohila, J. S., Subramanian, S., et al. (2016). A toolbox of genes, proteins, metabolites and promoters for improving drought tolerance in soybean includes the metabolite coumestrol and stomatal development genes. BMC Genomics 17:102. doi: 10.1186/s12864016-2420-0

Voisin, A.-S., Guéguen, J., Huyghe, C., Jeuffroy, M.-H., Magrini, M.-B., Meynard, J.-M., et al. (2013). Legumes for feed, food, biomaterials and bioenergy in Europe: a review. Agron. Sustain. Dev. 34, 361-380. doi: 10.1007/s13593-0130189-y

Voisin, A.-S., Salon, C., Jeudy, C., and Warembourg, F. R. (2003). Seasonal patterns of ${ }^{13} \mathrm{C}$ partitioning between shoots and nodulated roots of $\mathrm{N}_{2}$ or nitrate-fed Pisum sativum L. Ann. Bot. 91, 539-546. doi: 10.1093/AOB/ MCG055

Vollmann, J., Fritz, C. N., Wagentristl, H., and Ruckenbauer, P. (2000). Environmental and genetic variation of soybean seed protein content under Central European growing conditions. J. Sci. Food Agric. 80, 1300-1306. doi: 10.1002/1097-0010(200007)80:9<1300::aid-jsfa640>3.0.co;2-i

Watson, C., Reckling, M., Preissel, S., Bachinger, J., Bergkvist, G., Kuhlman, T., et al. (2017). Grain legume production and use in European agricultural systems. Adv. Agron. 144, 235-303. doi: 10.1016/bs.agron.2017.03. 003

Wilkinson, S., and Davies, W. J. (2009). Ozone suppresses soil drying- and abscisic acid (ABA)-induced stomatal closure via an ethylene-dependent mechanism. Plant Cell Environ. 32, 949-959. doi: 10.1111/j.1365-3040.2009.01 970.x

Yuan, K., Reckling, M., Ramirez, M. D. A., Djedidi, S., Fukuhara, I., Ohyama, T., et al. (2020). Characterization of rhizobia for the improvement of soybean cultivation at cold conditions in central Europe. Microbes Environ. 35:1. doi: 10.1264/jsme2.ME19124

Zaman-Allah, M., Sifi, B., L’taief, B., El Aouni, M. H., and Drevon, J. J. (2007). Rhizobial inoculation and $\mathrm{P}$ fertilization response in common bean (Phaseolus vulgaris) under glasshouse and field conditions. Exp. Agric. 43, 67-77.

Zander, P., Amjath-Babu, T. S., Preissel, S., Reckling, M., Bues, A., Schläfke, N., et al. (2016). Grain legume decline and potential recovery in European agriculture: a review. Agron. Sustain. Dev. 36:26.

Zhang, H., Prithiviraj, B., Charles, T. C., Driscoll, B. T., and Smith, D. L. (2003). Low temperature tolerant Bradyrhizobium japonicum strains allowing improved nodulation and nitrogen fixation of soybean in a short season (cool spring) area. Eur. J. Agron. 19, 205-213. doi: 10.1016/s1161-0301(02)00038-2

Zimmer, S., Messmer, M., Haase, T., Piepho, H.-P., Mindermann, A., Schulz, H., et al. (2016). Effects of soybean variety and Bradyrhizobium strains on yield, protein content and biological nitrogen fixation under cool growing conditions in Germany. Eur. J. Agron. 72, 38-46.

Conflict of Interest: The authors declare that the research was conducted in the absence of any commercial or financial relationships that could be construed as a potential conflict of interest.

Publisher's Note: All claims expressed in this article are solely those of the authors and do not necessarily represent those of their affiliated organizations, or those of the publisher, the editors and the reviewers. Any product that may be evaluated in this article, or claim that may be made by its manufacturer, is not guaranteed or endorsed by the publisher.

Copyright (c) 2022 Omari, Yuan, Anh, Reckling, Halwani, Egamberdieva, OhkamaOhtsu and Bellingrath-Kimura. This is an open-access article distributed under the terms of the Creative Commons Attribution License (CC BY). The use, distribution or reproduction in other forums is permitted, provided the original author(s) and the copyright owner(s) are credited and that the original publication in this journal is cited, in accordance with accepted academic practice. No use, distribution or reproduction is permitted which does not comply with these terms. 